\title{
Understanding social support in reunification: The views of foster children, birth families and social workers
}

\author{
M. Àngels Balsells* \\ Crescencia Pastor** \\ M. Cruz Molina** \\ Nuria Fuentes-Peláez** \\ Noelia Vázquez**
}

* Department of Pedagogy and Psychology, Faculty of Educational Sciences, University ofLleida, Lleida 25001, Spain

** Department of Education Methods and Diagnostics, Faculty of Education, University of Barcelona, Barcelona 08035, Spain

\begin{abstract}
Research suggests that the social support received from fathers and mothers is a key factor in the reunification process, particularly on a foster child's return home. However, little is known regarding the nature of this support, its sources and the aspects on which such support should be focused. The aim of this study is to describe the social support that families require at the time of a child's return to successfully re-establish the family positive dynamics, functioning and routines. This research is based on information gathered in Spain from a focus group and in interviews of 63 professionals, 42 parents and 30 children. The method is qualitative, and the ATLAS.ti program is used for content analysis. The qualitative data enable a better understanding of the views of the individuals involved. The results indicate the relevance of the support provided by the protection system and the social services. The results also reveal the insufficiency of the informal support network. These findings suggest implications for social workers when focusing post-reunification support on specific needs linked to parental skills, personal difficulties of the parents and the stability of the family context.
\end{abstract}


Keywords: Family Support, Child Protection, Children and families, Child welfare

\section{INTRODUCTION}

In terms of the child welfare system, family reunification is the process by which a child returns to his or her biological family after a period of temporary foster care resulting from abandonment, negligence, abuse or inadequate parenting. This process aims to help children and parents achieve and maintain optimal levels when re-establishing the relationship and to ensure the stability that boys and girls require for their personal and physical development (Child Welfare League of America, 2002).

In the UK, US and Canada, research on the process of reunification and the relevant legislative measures (Farmer \& Wijedesa, 2013) represents a model for reference and comparison for many European countries, including Spain, where this study was undertaken and where recent research has been increasing in recent years. In UK some authors identified that after de mid 1990 increased pres-sure on resources for children's services and also increased policies and practice context which highlighted that reunification is a relevant issue (Biheal, 2007). Recently, Lutman \& Farmer (2013) and Lutman and Farmer (2014) have contributed to understand more about the circumstances in which children are reunified and what helps returns to succeed. According to Delfabbro, Fernandez, McCormick and Kettler (2013), family reunification or restoration research is a well-established area of international research.

Kimberlin, Anthony, Berrick, Cohen and Wilder (2009) demonstrate how in the US family reunification is the ultimate goal according to federal social welfare laws. In fact, it is required that during the first 12 months after entering in foster care that the possibility of the child and the family being reunified be determined. The Adoption and Safe Families Act (US Department of Health and Human Services, Administration for Children and Families (HHS), 1998) obliges states to show that they have undertaken "reasonable efforts" to preserve families (i.e., to prevent children from leaving their homes) or to reunify them with their families if they have been withdrawn. Additionally, reunification should occur during the first 15 months that a child has been in foster care.

In the family reunification process, the return of the boys and girls to their homes and the reestablishment of family cohabitation represents a difficult and crucial moment. Despite reunification expectations, many families do not perform well. In EUA, a total of 51\% of boys 
and girls who depart the protection services do so to return to their parents or primary caregivers (Children Bureau, 2010). However, this return is not always successful. The statistics on the return to the protection system vary according to location and the year in which the research is conducted (Kimberlin et al., 2009). Wulczyn (2004) finds that whereas the number of failed reunifications is decreasing, $25 \%$ of cases that start with the return home subsequently return into the protection system within one year. Farmer and Wijedesa (2013) note the English case of return percentages oscillate between 37\% and 65\% depending on the duration of the research follow-up.

\section{BACKGROUND}

\section{The reunification process: Social support upon returning home}

Together with flexibility, communication, attitude and a child's capacity to interpret his or her own difficulties, the initiative to meet family needs, willingness, father involvement, family expressiveness, child cognitive ability, externalizing behavior and spirituality, social support has been considered to be a key protective factor in the reunification process (Balsells et al. 2011, 2013; DeFrain \& Asay, 2007; Dunst \& Trivette, 2009; Fuentes-Peláez et al., 2014; Lietz \& Strength, 2011; Proctor et al., 2011). Accordingly, working with the biological family in its context and considering the role played by social support sources are key conditions when applying a temporary protective measure within a family reunification prognosis. Without this intervention, the causes of abandonment or poor parenting are highly unlikely to disappear and are difficult to eliminate. Therefore, and because of the various factors associated with the success of family reunification, this study focuses on the role played by social support.

Spilsbury and Korbin (2013) propose that social support is the availability of the assistance of one person to another. This assistance can be the key to emotional, informational or instrumental resources emerging from the various social relations between individuals or groups (Cohen, 1985, 2000).

Social support is defined as the process by which social resources provided by informal and formal networks allow instrumental and expressive personal and family needs to be met in everyday situations (Lin \& Ensel, 1989).It is related with emotional, psychological, physical, informational, instrumental and material assistance provided by others to either maintain well- 
being or promote adaptations to difficult life events (Dunst \& Trivette, 1988). It is the combined social resources formal and informal support networks which help families to cope from day to day or in crisis situations (Fuentes et alt, 2014; Lin \& Ensel, 1989)

Social support is a key element during the entire reunification process, particularly during the phase of returning home. The support relied on by the various family members to positively address this unique moment of reunification and the re-establishment of family cohabitation has been associated with a lower rate of return to the protection system (Farmer \& Wijedasa, 2013). Kimberlin et al. (2009) demonstrate that the lack of social support represents a risk factor for successful reunification (Barth, Weigensberg, Fisher, Fetrow \& Green, 2008). Lin (2013) reinforces these ideas by providing evidence that the lack of different types of support hinders the ability of caregivers to care for the children and help children achieve permanent positive results.

The benefits of having or receiving support from various sources are associated with the prevention of relapses, the strengthening of the capacities of the family system (Lee, Bright, Svoboda, Fakunmoju, \& Barth, 2011) and the maintenance and improvement of family functioning (Lietz, et al., 2011; Ordoñez, 2009). These sources of support or help can come from the formal system or from informal networks. In the first case, formal support comes from professionals, services, agencies or institutions. In the latter, informal support comes from non-professional relations (e.g., friends or neighbors) (Spilsbury \& Korbin, 2013). Various studies (Kimberlin et al., 2009; Lee et al., 2011; Lietz \& Strenght, 2011) indicate that one factor that plays a prominent role in family reunification is the informal support that the families receive from their extended family, friends, neighbors and support groups as well as the formal support offered by the various services that are tasked with the protection of the minor and by social services.

Regarding formal support, the support obtained during out-of-school periods and mentoring or socio-educational programs for fathers and mothers have been identified as the most successful strategies in the reunification process (Barth et al., 2008). Similarly, although the family may reject support during the first, "honey-moon period” days after the child's return home, protection services professionals are recommended to continue insisting on offering support to assure a successful return (North Carolina Division of Social Services and the Family and Children's Resource Program, 2013). Evidence has demonstrated that the protection services that connect families with natural support networks and networks of 
formal support obtain more positive qualitative results in the process of a minor's return (Child Welfare Information Gateway, 2011).

Finally, regarding informal support, although such support is considered to be indispensable to the reunification process (Maluccio, 2000), various studies have found that families at risk (Rodrigo, Martin, Maiquez \& Rodriguez, 2007) and families under the care of the protection system (Fuentes-Peláez et al.., 2014) typically have a poor, insufficient network of informal support to call on when addressing the difficult circumstances and changes to which they must respond.

\section{RESEARCH AIMS AND METHODS}

The literature has demonstrated the importance of social support as a key element for consolidating reunification. However, the key social support elements at the time of the child's return home require additional investigation. This paper presents findings from a study that aimed to examine the social support required by fathers and mothers at the time of a child's return home to re-establish the family positive dynamics, functioning and routines and contribute to a successful reunification.

\section{Study design}

The design of the investigation is qualitative and has descriptive and explanatory aims. The perspective emphasizes parents, children and professionals as expert agents (Stolz, Brandon, Wallace \& Robenson, 2013) of the reunification process and indispensable to its improvement. This methodological design has been considered necessary to more thoroughly examining and better understanding the role of social support in the family process for families within the protection system (Lin, 2013). The approach used focus groups and conducting semi-structured interviews with multiple informants: professionals, parents and children.

\section{Participants}

The total sample was 135 individuals and included 42 parents in child welfare plans or recently reunited with a child (within one year), 63 childcare professionals and 30 children and adolescents who have undergone a foster process, whether kinship or residential. 
The focus group participants were selected according to different criteria. In the case of parents, the criteria were families who: a) were already reunited with their children or expecting a return within one or two months, b) had fulfilled or were fulfilling a reunification plan, c) were willing to collaborate with professionals and d) with different characteristics of age and family structure. For professionals, the criteria were professionals who: a) worked in infancy protection services, b) represented the different disciplines that constitute the professional teams, e.g., psychologists, pedagogues, social workers and educators and c) with experience in residential foster care or kinship care. Finally, for the children and adolescents, the criteria were as follows: a) between 12 and 20 years old and belonging to selected biological families, b) at least one year in care (foster care or residential care) or in kinship care and c) no physical, mental or sensory disability that would prevent participation in the focus group.

Thus, in the case of the parents, the final sample was $76.2 \%$ female and $23.8 \%$ male. A total of 34 parents represented reunited families, whereas four parents were from families who had not reunited. Of the childcare professionals, 20 were social educators, 10 were teachers, 20 were psychologists and 13 were social workers. A total of $74.6 \%$ were female, and $25.4 \%$ were male. A total of $25.80 \%$ were between 25 and 35 years old, $45.16 \%$ were between 36 and 45 years old, and $29.04 \%$ were over 46 years old. Of these, 33 were professionally engaged in biological family intervention, 16 in residential foster care intervention and five in kinship care intervention. Of the children and teenagers, 21 were reunited and nine were not. A total of $53.3 \%$ were girls and $46.7 \%$ were boys. A total of $17 \%$ were between six and 12 years old, 56\% were between 12 and 18 years old and $27 \%$ were adults.

\section{Data collection}

To gather the data, the focus group technique and semi-structured interviews were used. : Issues related to kinship foster care were addressed using the following written criteria. This approach has been considered to be adequate for vulnerable population groups (Ayon and Kiroz, 2013), in particular families in the protection system (Balsells et al., 2011), and for professionals who work with families (Stolz et al., 2013). The tools used to gather the data were of three types: (1) an identification card with the participant's basic data, (2) guidance on questions for the development of the discussion group or semi-structured interview and (3) a summary card for the discussion group in which aspects related to the development of the 
group were registered: date, length, location, motivation, cohesion, atmosphere, group dynamics and how the questions functioned.

A total of 18 interviews were conducted, and 22 discussion groups were formed. Two researchers from the team travelled to each office of the social services experts. One researcher had the role of moderator, whereas the other was in charge of the logistics and recording the discussion following the written criteria. Each discussion group and interview was recorded with the agreement of those present and with a confidentiality agreement.

\section{Data analysis}

The analysis focused on identifying and explaining the social support that fathers and mothers require on the return of their sons or daughters to the household and that is considered important to a successful reunification. The process used to analyze the information was content analysis using prepared codes that were evaluated by different judges.

Bottom-up content analysis was applied. The first stage of analysis was textual. Paragraphs, fragments and significant quotations from the transcription papers were selected. The second stage was conceptual and used to identify categories and subcategories that could be interrelated. Both stages were performed and subjected to peer review, and the categories and subcategories were defined when the data reached saturation.

ATLAS.ti 6.0 software was used for the qualitative data processing. A hermeneutic unit editor was created in which the literal transcriptions of the focus group discussions and the interviews (i.e., the primary documents) were included. Each category was provided a code (code). Textual notes were also included (memos). A conceptual network (network) was created to analyze the data as a basis for the connections established between the hermeneutic unit codes.

The analysis code recognized categories related to the social support needs of the fathers and mothers during the child's first days at home: (1) formal support [(1.1) formal support within the protection system and (1.2.) formal support outside of the protection system] and (2) informal support. All the data was collected and analyzed with the IRB approval (IRB00003099). 


\section{RESULTS}

The content analysis of the opinions of the professionals, fathers and mothers and boys and girls regarding parental support needs upon the child's return home enabled the identification of four categories, which represent the sources of social support: (1) formal support within the child protection system, formal support services outside of the child protection system and (3) informal support (4) Convergence between formal and informal support. The results indicate how these three sources of support are directed to cover three substantial spheres of parental needs at the time of the child's return: (A) personal needs related to difficulties faced by parents, (B) structural needs related to the immediate family context and (C) needs in the area of parental skills development (Figure 1). As developed below, the interaction between these needs and the sources of social support will support the well-being of the child and the stability of the reunification.

Figure 1: Categories that arose from content analysis and the basic needs to which they respond

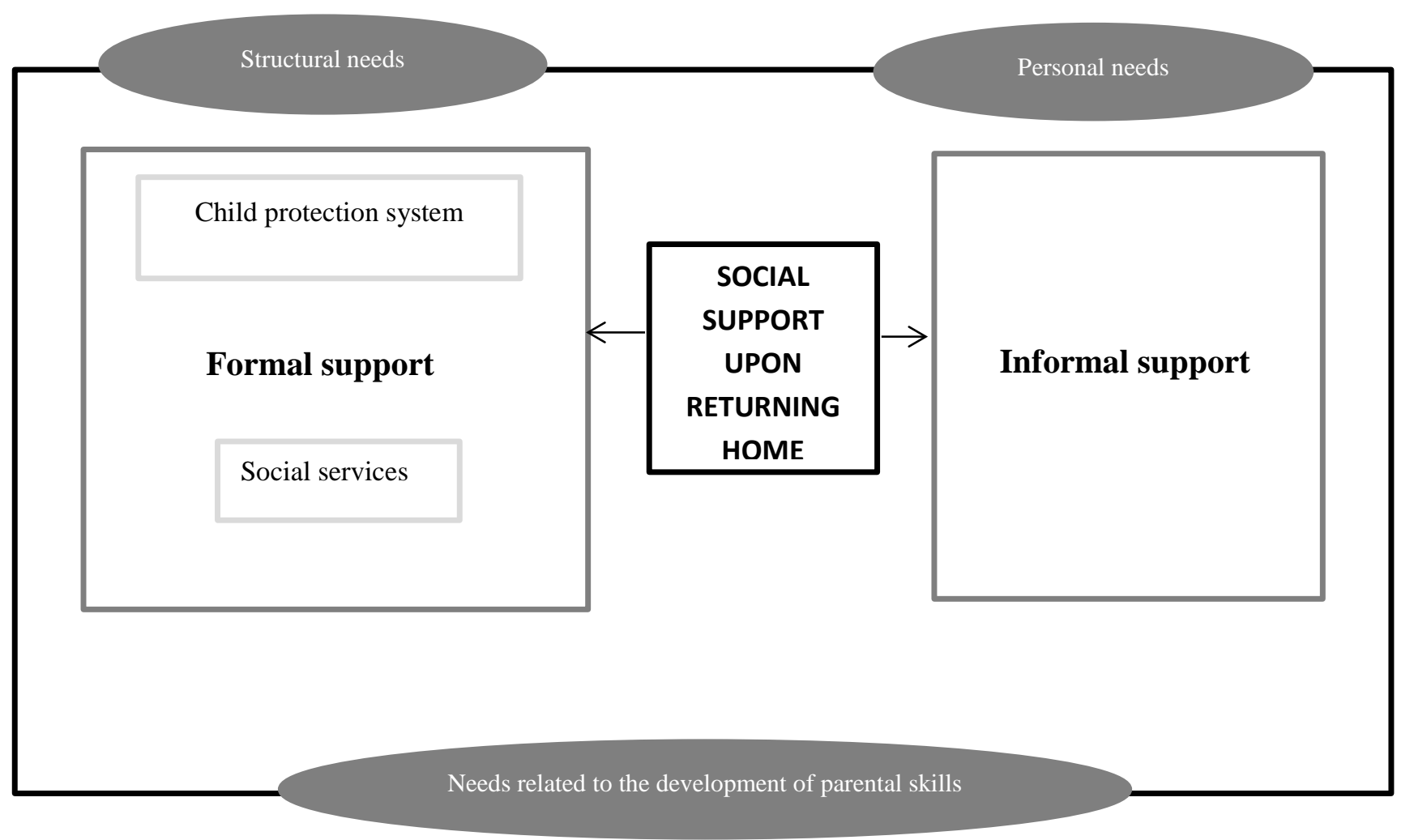




\section{Formal social support within the protection system}

One finding that was important because of its recurrence among the participants is the need of fathers and mothers for more follow-up on the return home by child protection system professionals. The participants indicated that in many cases, there is no continuity with the intensive follow-up that was received in the months prior to the return home. However, the results suggest that it is necessary to view the reunification process. The return home is another and not the final stage of the process because various challenges remain to be overcome for healthy family cohabitation. This lack of support is associated with the saturation of services, which does not allow for follow-up in all cases, or the failure to follow protocol in terms of what services should and can be provided during this follow-up.

(A professional) There isn't a single family educator in any municipal office; above all, this problem occurs in small offices; so, there are difficulties when the return occurs, and afterward, there is no local support, and there has to be continued support from the minors' center, but this is not possible in all cases. (...) We do not make it; we have many cases.

Thus, families refer to both the continuity of contact with the reference person during the foster care period and to the professional figure who is handling their case:

(A parent) Sure, it's like I have been left all to myself; I was used to having interviews and the psychologist and everyone... and sure, you feel a bit on your own; who do you ask what you should do?

The families require support from child protection system to establish a family dynamic based on developing positive parenting. Fundamentally, during the first stage of a reunification, the family applies parental skills. After the time of separation, doubts arise regarding how to manage the returning child's developmental changes. Additionally, the change undergone by various family members since the time of separation leave parents occasionally feeling lost and in need of support.

(A professional) The parents are in a poor state, some with little personal skills and with less still in terms of parental skills, and there are not enough resources for parents for them to learn how to be parents.

\section{Formal support from outside child protection system social}


Social support from social services acquires a special meaning at this stage of reunification. The results indicate how the reunification of children with their families creates needs that cause such families to seek support and support networks to satisfy those needs. The support serves two large groups of needs. The first group of needs is related to overcoming the personal difficulties of parents that cause in abuse or negligence. The other group of needs involves resolving structural problems and thereby creating a stable, structured environment for raising and caring for children.

Drug addiction, alcoholism, violence, mental illness or another type of psychological weakness is typically found among the causes of a child's out-of-home care. When a child returns home, these problems were overcome. However, fathers and mothers require support resources to consolidate and this progress. The child's return home is a significant change for parents who have been without the child for a considerable period. The personal fragility caused by their personal difficulties enters a critical moment in this phase and necessarily justifies formal support from the health, psychological, social, educational and labor system.

(A child) And the best has been this psychologist (...). This person is helping you a lot to control yourself better. Yes, and for my parents too.

(A parent) For me, the Project Man [Proyecto Hombre] is as if it were my house. For me... they have helped me in everything... Even now, if I have any problems, I can call, and they provide support...

Similarly, the results reveal how parents demand support to ensure the material conditions that will enable the return home stable and safe. On many occasions, families speak of unemployment, conditions of lack in their homes and economic difficulties that jeopardize the stability required by childhood. These comments that occur in the discourse of various participants express the need for material or economic support. The comments refer, for example, to nurseries, recreational services and free time as well as economic contributions for basic supplies.

(A parent) Because of course this help is supposedly 200 and more euros for each child, for the expenses they have, right? But then you have to tell yourself, "ok, the costs they have, but there I have to include water, electricity and rent? Or not? Or just for buying things for them?” 
They also suggest that educational support is needed to achieve this stability. The professionals state that families require information regarding the resources available and training on how to use them adequately and within appropriate limitations. Overproviding resources may result in saturating the family with information, which creates roadblocks for the family, confuses it and makes work with the family more difficult. Knowing how to adequately use and manage resources is not only identified as progress in terms of family stability but also as the capacity of families to be autonomous and normalize their situation.

(A professional) I think that many resources we have we do not use well; or we get parents in touch with many resources when a good case study could be made, with one or two, it would be enough, (...) and many times this leads to a saturation, which makes families close up, and then they really do not take advantage of the resources they need.

\section{Informal support}

The research results reveal that in all of the discourses of the participants, there is an important absence of informal social support. Extended family, friends, neighbors or other close persons are typical absent from the discourse of the participants. The fathers and mothers display a need for increased support from extended family and request contact with other families that are in similar situations.

The informal support for overcoming personal difficulties is provided nearly exclusively by the partner or spousal relationship, if there is one (e.g., wife/husband, girlfriend/boyfriend). Emotional help is the specific type of informal support provided, which is focused on overcoming personal difficulties. This emotional help in overcoming difficulties comes from the romantic relationship, if there is such a bond.

(A parent) My partner, because if I didn't have her, I would have never gotten the child back. If not, I work in hospitality for 12 hours a day, if I didn't have a partner, I would never have recovered my son.

The couple and the emotional support that this relationship provides should be included in the family work, while analyzing the strengths and weaknesses of this support, so the reunification process can be truly beneficial. 
(A professional) I think it would be important to see how the couple is at the emotional and trust level, handling this factor, with analysis of the couple's strengths and weaknesses.

The results indicate how, on occasion, the extended family is an important source of informal support to the biological family for promoting stability and helping meet material needs for the child's return home. However, in this type of support, material help is also referenced and includes clothes, housing and basic staples offered by members of the extended family, such as brothers or grandparents.

\section{Convergence between formal and informal support}

Finally, both families and professionals indicate that the formal support received from the protection system during the child's first days home should translate into the formation of groups of parents who are experiencing (or have experienced similar situations). All of the families and professionals indicate that this approach would enable families to feel greater support and would favor the process of re-adaptation. This support can be translated into informal support from the peer group.

(A professional) I think they are very defenseless; perhaps if someone is going through the same thing or has gone through this, they could talk to them; it would be interesting.

Certain parents speak from the position of expert and others from the position of pupil. However, all are parents during family reunification. The peer group support is considered to be useful to answer the three main needs during the child's first days home: structural needs, personal needs and the need for parental skills.

\section{DISCUSSION AND IMPLICATIONS FOR SOCIAL WORK}

This study provides the perspectives of key people involved in the important period of the child's return home in the reunification process. These views from parents, children and professionals contribute to broadening our knowledge regarding the reunification process and converge in emphasizing that social support is a relevant factor in the post-reunification phase. This study has enabled us to locate and outline the specifics of this support. 
The aim of this study was to investigate the social support that mothers and fathers require to establish a functional family dynamic and contribute to a successful reunification process when a child returns home. Although the availability of this support during the first days of the child's return has been strongly related to a better reunification prognosis (Proctor et al., 2011), social support should focus on the practical ways in which families can attend to their highly specific needs. This study about Spanish families reinforces the international findings of the USA Child Welfare Information Gateway (2012), which examines the nature of the social support present during the post-reunification period. USA and North European Welfare System families' research is large and long-standing, however in Spain this kind of research is incipient. According to that is recommended to use an international perspective to contrast the national findings looking for the similarities in how Spain and other countries deal with this important social situation impacting families similarly.

Related to this, this study clearly demonstrates that the primary need of Spanish families is continuity in the support provided by the child protection system during the return phase. These results agree with the findings of Connell, Vanderploeg, Katz, Caron, Saunders and Tebes (2009), who state that the risk of relapse during the return home requires protocols in which the child protection system's support role for families is specified. A need for continuity between the reference professional during the foster care stage and the reference professional who provides support for the training needs of the family on a day-to-day basis is observed. This support should be focused on the development of parental skills and adaptation to the changes undergone by various family members since the separation.

Another contribution of this study is its discovery of two important areas of attention in which community services should act in coordination: help in satisfying personal needs and help in attending to the structural needs of families. The quality of services to which there is access is described as a better predictor of results than the quantity of such services (Ungar, 2013). Families require psychological and material support as well as training support to access and manage the various support resources. In this context, our results clearly find the relevance of establishing a reference person who can offer the necessary information and resources, thus avoiding the improper use of resources and the saturation (or the rejection) of families with an excessive quantity of help, which does not guarantee their stability. Social workers have an important role on that. 
From an ecological perspective, the development of parenthood concerns the interaction between the psychosocial context, parental skills and childhood needs (Drake, Johnson-Reid \& Sapokaite, 2006; Fisher, Burraston \& Pears, 2005; Milani, Serbati, Ius, Di Masi, \& Zanon, 2013; Rodrigo, Maiquez \& Martin, 2010). The results indicate how the participants in the reunification process situate their needs relative to these three levels of various services supplied by the formal support network. Thus, child protection services play a relevant role in adapting and reformulating parental skills when a child returns home, whereas community services provide support for the needs that arise in the family context and in attending to the returning child's needs.

This multiple assistance from formal support sources is accompanied by insufficient informal support. Families who experience complex social situations display deficits in the availability of help that they receive from friends, family members and other sources of informal support (Lin, 2013). This deficit is compensated for by excessive assistance from formal resources, which does not favor the development of family autonomy (Rodrigo et al., 2007). Empowering families so that they can be agents of support for other families can be a way to consolidate reunification (Balsells et al., 2015). This mixed way could provide some of the formal and informal support benefits.

Our findings reinforce these ideas from different European and American studies and demonstrate the need to establish strategies that promote the creation and strengthening of informal networks.

In this context, there are two main implications for social work:

1) The first relates to highlight the importance of the development of groups of fathers and mothers who are experiencing the reunification process. These groups provide a good opportunity for initial follow-up and support, including in making available socio-educational work with professionals in the child protection and family support system. Additionally, these groups can provide opportunities for parents in more advanced stages of reunification to provide help to and receive help from parents who are beginning, which could be consolidated as an informal support source. This support reciprocity has been mentioned by the participants of this Spanish research and is coherent with international findings of Lietz (2011), which indicate that support from other parents can be a means to strengthen families in the process of reunification. 
2) The second relates to facilitating the positive relation between the various social support sources while actively and definitively including the informal support network. The role of positive relations between the different levels of support has been identified as a relevant element for preventing situations of abuse and as resulting in improved child well-being (Holland, 2012). Given the evidence, the practices aimed at including neighbors, the community and the social services in the care for the child seem to be particularly called for when the returning children have previously experienced abandonment.

To conclude, we would like to emphasize that this study has facilitated specifying and profiling the what and the how of social support that is required by families in the return-tohome stage of the family reunification process. To re-establish the family dynamic and cohabitation following the provisional separation, the development of parental skills is necessary. Improved parenting skills enable parents to identify the changes in their son or daughter after the provisional separation and then to adapt the norms, routines and family roles of everyday life in order to appropriately meet the child's developmental needs and promote family stability. Formal and informal networks can be useful for re-establishing the family dynamic and fulfilling the needs of the child, those of the parents and of the family as a whole, thereby valuing the nuclear and extended family as a source of support for its members. As we have seen these Spanish findings are consistent with different international studies. This allow us to walk together identifying similarities between different countries in family reunification process promotion.

\section{Acknowledgements}

This study has been developed by the investigation group GRISIJ (Research Group in Socialeducational Child Intervention) and financed by the Spanish Ministry of Science and innovation (EDU2011-00144-C02-01), the Department of Universities, Research and Information Society of the Government of -Catalonia (2009SGR 1392), ARCE (Research Aggrupation in Educational Science), the University of Barcelona and the University of Lleida.

\section{REFERENCES}


Balsells, A., Amorós, P., Fuentes-Peláez, N. and Mateos, A. (2011). Needs Analysis for a Parental Guidance Program for Biological Family Spain Current Situation. Revista de Cercetare si interventie sociala, 34, 21-37. Retrieved from http://www.psicothema.com/pdf/4122.pdf

Balsells, M. A., Pastor, C., Mateos, A., Vaquero, E. and Urrea, A. (2015) Exploring the needs of parents for achieving reunification: The views of foster children, birth family and social workers in Spain. Children and Youth Services Review, 48, 159-166. Retrieved from http://www.sciencedirect.com/science/article/pii/S0190740914004289

Balsells, M. A., Pastor, C., Molina, M. C., Fuentes-Peláez, N., Vaquero, E. and Mundet, A. (2013) Child welfare and successful reunification understanding of the family difficulties during the socio-educative process. Revista de cercetare interventione sociales, 42, 228-247.

Barth, R.P., Weigensberg, E.C., Fisher, P.A., Fetrow, B. \& Green, R.L. (2008) Reentry of elementary aged children following reunification from foster care. Children and Youth Services Review, 30, 353-364

Biehal, N. (2007): Reuniting Children with their Families: Reconsidering the Evidence on Timing, Contact and Outcomes. British Journal of Social Work, 37,807-823

Child Welfare Information Gateway (2011) Family Reunification: What the Evidence Shows. U.S. Department of Health and Human Services Administration for Children and Families Administration on Children. Washington, DC: U.S. Department of Health and Human Services, Children’s Bureau.

Child Welfare Information Gateway. (2012). Supporting reunification and preventing reentry into out-of-home care. Washington, DC: U.S. Department of Health and Human Services, Children's Bureau.

Children's Bureau. (2010). The AFCARS report: Preliminary FY 2009 estimates as of July 2010. Washington, DC: U.S. Department of Health and Human Services, Administration for Children and Families. Retrieved January 2013 from www.acf.hhs.gov/programs/cb/stats_research/afcars/tar/report17.htmChild Welfare League of America (2002) Family Reunification. Washington, DC.

Connell, C.M., Vanderploeg, J.J., Katz, K.H., Caron, C., Saunders, L. \& Tebes, J.K. (2009). Maltreatment following reunification: predictors of subsequent Child Protective Services contact after children return home, Child Abuse Negl. 33(4), p.218-228.

Defrain, J. \& Asay, S. (2007). Strong families around the world: The family strengths perspective, New York: Haworth Press. 
Delfabbro, P., Fernandez, E., McCormick, J., \& Kettler, L. (2013). Reunification in a complete entry cohort: A longitudinal study of children entering out-of-home care in Tasmania, Australia. Children and Youth Services Review, 35, 1592-1600. doi:10.1016/j.childyouth.2013.06.012

Drake, B., Jonson-Reid, M., \& Sapokaite, L. (2006). Rereporting of child maltreatment: Does participation in other public sector services moderate the likelihood of a second maltreatment report? Child Abuse \& Neglect, 30, 1201-1226

Dunst, C. J., \& Trivette, C. M. (1988). Toward experimental evaluation of the family, infant and preschool program. In H. B. Weiss \& F. H. Jacobs (Eds.), Evaluating Family Programs (pp. 315-346). New York: Aldine De Gruyter.

Dunst, C.J. \& Trivette, C.M. (2009). Capacity-building family systems intervention practices. Journal of Family social Work, 12, 119-143.

Farmer, E. \& Wijedesa, D. (2013) The Reunification of Looked After Children with Their Parents: What Contributes to Return Stability? British Journal of Social Work , 43, 1611-1629 http://doi:10.1093/bjsw/bcs066

Farmer, E. (2014). Improving Reunification Practice: Pathways Home, Progress and Outcomes for Children Returning from Care to Their Parents. British Journal of Social Work , 44 (2), 348-366

Fisher, P. A., Burraston, B., \& Pears, K. (2005). The early intervention foster care program: Permanent placement outcomes from a randomized trial. Child Maltreatment, 10, 6171.

Fuentes-Peláez, N., Balsells, M., Fernández, J., Vaquero, E. \& Amorós, P. (2014). The social support in kinship foster care: a way to enhance resilience. Child \& Family Social Work. http://doi: 10.1111/cfs.12182

Geen, R. (2003). Foster children placed with relatives often receive less government help. New Federalism. Issues and options for States. The Urban Institute, p. 1-6. Washington, DC. Retrieved from http://www.urban.org/UploadedPDF/310774_A59.pdf

Holland, S. (2012). Trust in the Community: Understanding the Relationship between Formal, Semi-Formal and Informal Child Safeguarding in a Local Neighbourhood. British Journal of Social Work, 4 (2), 384-400.

Kimberlin, S.; Anthony, E., Berrick, J.D., Cohen, E., \& Wilder, E. (2009). Partnering with parents: Promising approaches to improve reunification outcomes for children in 
foster care. Unpublished manuscript. University of California, Berkeley, School of Social Welfare Child

Lee, B. R., Bright, C. L., Svoboda, D., Fakunmoju, S., \& Barth, R. P. (2011). Outcomes of group care for youth: A review of comparative studies. Research on Social Work Practice, 21, 177-189

Lietz, C.A., Lacasse, J.R. \& Cacciatore (2011). Social Support in Family Reunification: A Qualitive Study. Journal of Social Work, 14 (1), 3-20.

Lietz, C.A. \& Strength, M. (2011). Stories of Successful Reunification: A Narrative Study of Family Resilience in Child Welfare. Families in Society: The Journal of Contemporary Social Services, 92, 203-210.

Lin, (2013). Evaluating Services for Kinship Care Families: A Systematic Review. Children and Youth Services Review, 36, 32-41.

Lin, N. \& Ensel, W. M. (1989). Life stress and health: Stressors and resources. American Sociological Review, 54(3), 382-399. Doi: 10.2307/2095612.

Lutman \& Farmer (2013)What Contributes to Outcomes for Neglected Children Who Are Reunified with Their Parents? Findings from a Five-Year Follow-Up Study. British Journal of Social Work, 43, British Journal of Social Work

Maluccio, A. N. (2000). What works in family reunification. In M.P. Kluger, G. Alexander and P.A. Curtis (eds.), What works in Child Welfare, pp. 163-171. Washington, DC: Child Welfare League of America.

Milani, P., Serbati,S., Ius, M., Di Masi, D. \& Zanon, O. (2013) P.I.P.P.I. Programma di Intervento Per la Prevenzione dell'Istituzionalizzazione. LabRIEF Laboratorio di Ricerca e Intervento in Educazione Familiare. Padova.

North Carolina Division of Social Services \& the Family and Children's Resource Program (2013). Family reunification in North Carolina, Children's Services Practice Notes, 18 (3), $1-10$

Ordoñez, M.D. (2009) Factors que influyen en el éxito de la family reunification. Revista internacional de Ciencias Sociales and Humanidades, SOCIOTAM, 19 (1), 139-161. Retrieved from http://www.redalyc.org/pdf/654/65415751007.pdf

Proctor, L.J., Van Dusen Randazzo, K., Litrownik, A.J., Newton, R.R., Davis, I.P. \& Villodas, M. (2011) Factors associated with caregiver stability in permanent placements: A classification tree approach. Child Abuse and Neglect, 35, 425-436

Rodrigo, M.J., Martin, J.C., Maiquez, M.L. \& Rodríguez, G. (2007) Informal and formal supports and maternal child-rearing practices in at-risk and non at-risk psychosocial 
contexts. Children and Youth Service Review. 29, 329- 347. Retrieved from http://www.sciencedirect.com/science/article/pii/S0190740906001708

Rodrigo, M.J., Maiquez, M.L \& Martin, J.C. (2010) Parentalidad positiva and políticas locales de support a las families. Orientaciones para favorecer el ejercicio de las responsabilidades parentales desde las corporaciones locales (1 ed.). Federación Española de Municipios and Provincias. Ministerio de Sanidad and Política Social. Madrid. $\quad$ Retrieved from http:/www.femp.es/files/11-1608fichero/folleto\%20parentalidad\%2021x24\%20para\%20web.pdf

Spilsbury, J.C. \& Korbin, J.E. (2013) Social Networks and informal social support in protecting children from abuse and neglect. Child abuse and Neglect, 37, 8-16

Stolz, H.E., Brandon, M.D.J., Wallace, M. \& Roberson, P. (2013) Understanding and Addressing the Needs of Parenting Educators: A Focus Group Analysis. Families in Society: The Journal of Contemporary Social Services, 94(3), 203-210

Ungar, M. (2013). Resilience after maltreatment: The importance of social services as facilitators of positive adaptation. Child Abuse \& Neglect, 37, 110-115

U.S. Department of Health and Human Services, Administration for Children and Families (1998). Program Instruction PI-98-02: Public Law 105-89: The Adoption and Safe Families Act of 1997.

Wulczyn, F. (2004) Family reunification. The Future of Children, 14 (1), 95-113 